\title{
INTELLIGENT DEVELOPMENT OF BIG DATA ANALYTICS FOR MANUFACTURING INDUSTRY IN CLOUD COMPUTING
}

\author{
Dr. Abul Bashar, \\ Department of Computer Engineering, \\ Prince Mohammad Bin Fahd University, \\ Al Khobar, Kingdom of Saudi Arabia - 31952. \\ Email: abashar@pmu.edu.sa
}

\begin{abstract}
Big-data analytics being a useful technique in the analyzing the deeper values hidden inside a huge set of data flow that are generated in our day today lives, has almost become more prominent in variety of applications such as industrial development, smart home to smart city development and security management etc., despite its high potentials the challenges incurred makes it insufficient with certain applications that include a real time monitoring, so the paper proposes the real time monitoring of the developing manufacturing industry by proffering the intelligent big data analytics and cloud computing to present with the maximum possible insights to improvise the process of the manufacturing, by retaining the product consistency, optimal throughput and increasing the productivity.
\end{abstract}

Keywords: Intelligent big data analytics, data analytics, artificial intelligence, cloud computing, product consistency, optimal throughput.

\section{INTRODUCTION}

Whenever people come across the term big, they immediate thought the flashes the mind is the size. In our day today life activities each activities based on our daily routines and the other procedures bring in a huge flow of data known as the big data, all these data where once considered to be junk is cleaned, processed analyzed and utilized in future developments by the method of analytics, the big data analyzed for causing an impact or an improvement is called the big data analytics, the big data analytics are termed to be the significant for the future parallel and the distributed computing as the size of the data reserves and the volume of data in it keep on increasing day by day [2] , moreover the emerging technological progress is also leading to an avalanche of data flow from multitude of fields such as health care, social media, industries and supply chain. They turn out to be more prominent in providing the deeper insights of the data procured in our day today life on various context [4]. The big data incorporated with the

ISSN: 2582-337X (online) 
Journal of Ubiquitous Computing and Communication Technologies (UCCT) (2019)

Vol.01/ No. 01

Pages: $13-22$

https://www.irojournals.com/jucct/

DOI: https://doi.org/10.36548/jucct.2019.1.002

analytics and the artificial intelligence enables us to have a deeper knowledge on the data sets acquired paving way for intelligent decision making in the required fields [5] the figure.1 below represents the intelligent big analytics as the intersection of the big data, analytics and the artificial intelligence that poses the machine learning capabilities.

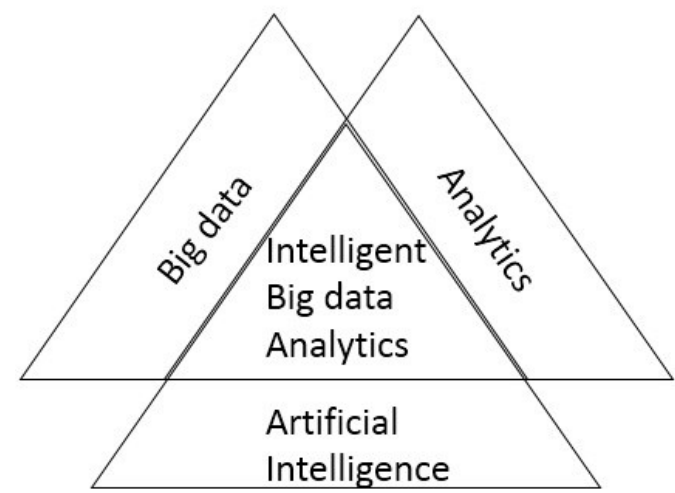

Fig .1 Essential Components of Intelligent Big data Analytics

In the recent days the big data and the artificial intelligence has become a popular and a most useful technology, to bring out the deeper impacts of the data and the values of the data in have considerable progress. The big data analytics help out in the development of the applications that are intelligent and capable of meeting out the user needs.

The paper also develops an intelligent big data analytics that is the combination of the big data, analytics and the artificial intelligence for a manufacturing industry of the daily based requirements of the common people and put forth a efficient management using the cloud computing.

The remaining paper proceeds with the 2 . The related works on the big data, analytics, artificial intelligence and the cloud computing facilities. 3 the proposed work developing intelligent big data analytics for the developing manufacturing industry that focuses on producing the common people requirements 4 . Includes the result and the discussion, 5. The Conclusion

ISSN: 2582-337X (online)

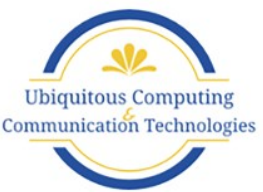


Journal of Ubiquitous Computing and Communication Technologies (UCCT) (2019)

Vol.01/ No. 01

Pages: $13-22$

https://www.irojournals.com/jucct/

DOI: https://doi.org/10.36548/jucct.2019.1.002

\subsection{PROBLEM DEFINITION}

Consider a developing manufacturing industry that produces the daily requirement of the common people, might be the toiletry set, perfumes or talcum powder etc. The industry head needs to have detail information starting from the market demand until the final stage of the product. Apart from the details for producing the product, the person needs to be aware of the daily routines taking place in the industry to further develop his industry, to improve the product quality and maintain the consistency of the product, further cutting down the mishappenings and the production cost. This could be done by the real monitoring of the manufacturing industry. The proposed process of intelligent big data analytics and the cloud computing ensures a real time monitoring of the manufacturing industry to have a considerable enhancements in the productivity and the product quality.

\section{RELATED WORKS}

The big data, that refers to the size of the data flow is been provided with a wider definition describing the characteristics of the big data that detail its uniqueness along with the focus on the analytical methods used are presented by the Gandomi et al [1] and Kambatla et al [2] presents the emerging trends of the big data analytics that are more compatible for the parallel and the distributed systems. Further the Hu et al [3] presents a technical tutorial of scalable system for the big data analytics by providing the literature survey and the sequential model of the big data systems. Raghupathi et al [4] explores the capability of the big data in the health care industry along with the discussion of the challenges involved in it. Dai et al [5] gives the survey on the details of the challenges involved in the big data analytics in manufacturing internet of things in one phase and proceeds with the enabling technologies of the big data analytics in the manufacturing of the data. To improvise the methods of analysing to derive the deeper insights from the sets of the data procured the Leenen et al [6] has proposed the integration of the AI and the big data in the cyber defense to visualize the data deeply and further cause improvement in the behavior by the intelligent decision making. Kibria et al [7] the utilization of the big data, analytics and the artificial intelligence for the future wireless networks, Zhu, et al [8] presents the big data analytics in developing an intelligent transportation system. De La Fuente et al [9], the application of the intelligent big data analytics in the discovery of the TBDs Chiang, et al [10] gives the details of the strategic values of the big data analytics to improve the decision making. Wang et al [11] presents the cloud computing capabilities in the management and the computing of the data procured by the remote sensing.

ISSN: 2582-337X (online) 
Journal of Ubiquitous Computing and Communication Technologies (UCCT) (2019)

Vol.01/ No. 01

Pages: $13-22$

https://www.irojournals.com/jucct/

DOI: https://doi.org/10.36548/jucct.2019.1.002

\section{PROPOSED WORK}

The capability of the big data, analytics has made it more significant among the multiple applications that aim in maintaining the progressive development of the respective fields. It has caused a major impact in almost many industries such as government, retail, health care and the financial services. The analyzing of the big data produced by the manufacturing industry enables it to cut down a production flaws and overcome the challenges in the manufacturing to a certain extent and enhances the productivity by saving the time and the cost. The fig .2 below shows the challenges in the manufacturing industry and the proposed method details the intelligent big data analytics that include the procurement of the big data, the analysis of the data procured using the data analytics and the artificial intelligence in deriving the possible insights from the data set and providing a real time monitoring using the in the cloud computing.

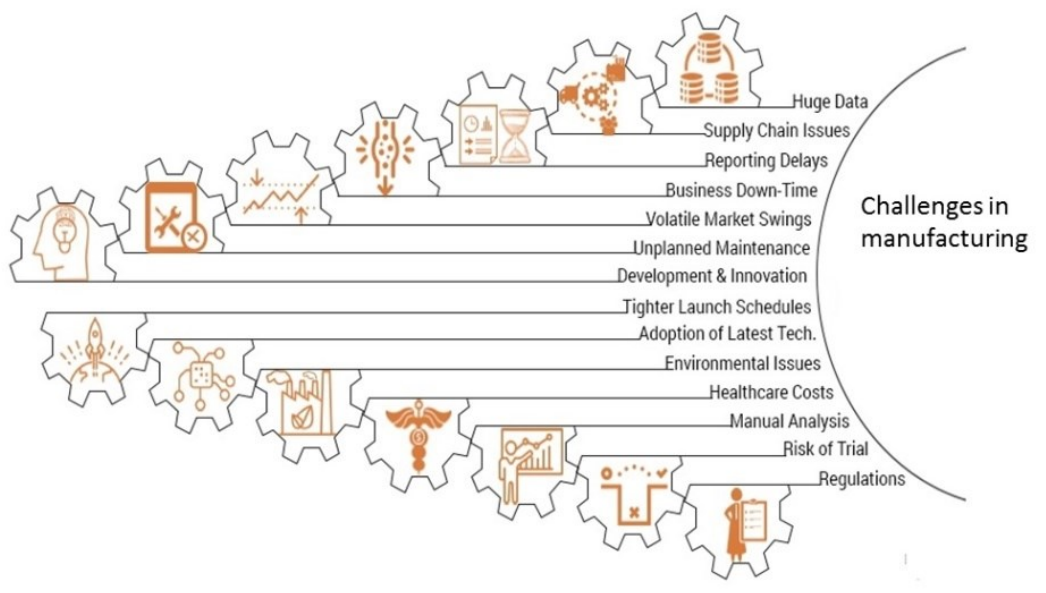

Fig .3 Challenges in Manufacturing [12]

The though enormous data flow are accumulated in the industry from each department, such as the user requirements, ERP, CRM extra, the developing industry would find itself hard in maintaining the product consistency and the productivity, reducing the production cost and the time of the manufacturing. So the real time

ISSN: 2582-337X (online) 
Journal of Ubiquitous Computing and Communication Technologies (UCCT) (2019)

Vol.01/ No. 01

Pages: $13-22$

https://www.irojournals.com/jucct/

DOI: https://doi.org/10.36548/jucct.2019.1.002

monitoring proposed with the cloud computing and the big data analytics that is intelligent scopes with the gathering of the necessary information's to identify the valuable insights and proceed transferring the live information tracked to the cloud computing for storage and the necessary actions.

\subsection{INTELLIGENT BIG-DATA ANALYTICS}

The intelligent big data analytics in the process of the improvising the production capability of the developing manufacturing industry, improves the process proceeding with the multiple strides that paves way for the up grading of the industry and retaining of the reputation eluding the confusion in the production that leads to the cutting down of the production. The fig. 3 below details the flow of the proposed process in the intelligent big data analytics paving way for an enhancement in the production level.

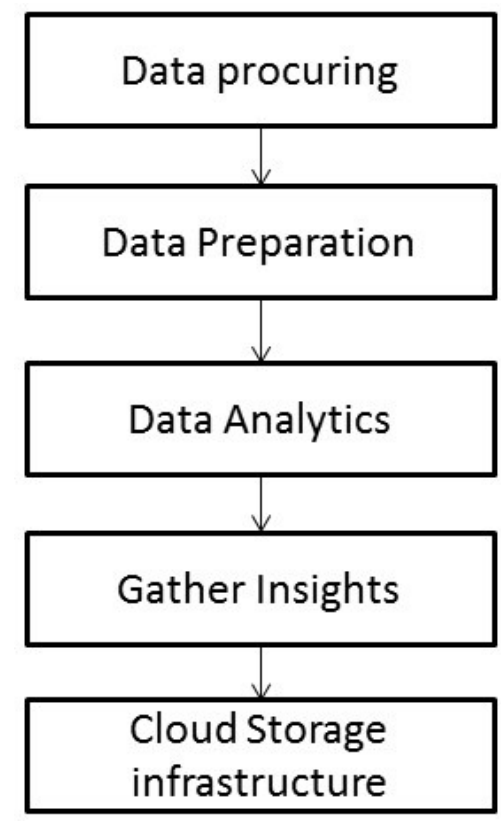

ISSN: 2582-337X (online) 
Journal of Ubiquitous Computing and Communication Technologies (UCCT) (2019)

Vol.01/ No. 01

Pages: $13-22$

https://www.irojournals.com/jucct/

DOI: https://doi.org/10.36548/jucct.2019.1.002

Fig .3 Proposed Flow Diagram

The data procurement initially starts with the feeds backs gathered from the users based on the requirement of the product. The data is gathered through the internet directly from the users or the retailers who reflect the user requirement, further the data of from the various sections of the industry are procured deploying the sensors for the monitoring of the shop floor, the machine health, energy utilization, ERP systems, CRM and MES systems etc. are gathered in its raw format, The data in the raw format has to be cleaned and transformed to further proceed retrieving of the valuable insights. The raw form of data procured are proceeded with the next stage of the data preparation that initiates the cleaning [4] and the transforming of the data, the proposed process employs the python script in data cleaning process to remove the unwanted details and transform the raw data into a relevant information. The whole process of cleaning the raw data procured form various source through the steps of extract, load and transform, utilizes the python with the regular expression and convert them into the relevant information and are stored in the data base.

Once the data are been procured and cleaned it is applied with the machine learning process, text analytics, data mining NLP are engage for mining of the data and predicting the deeper knowledge hidden inside. This process of applying the machine learning process for retrieving of the deeper knowledge hidden inside is known as the data analytics, the big data procured is analyzed for deeper knowledge of the industry. Where the machine learning trains the equipment's of the industry with the self-learning capability, the text analytics ensure the retrieving of the valuable information by diagnosing the patterns. Further the mining allows discovering the knowledge embedded within the information gathered and the NLP retrieves and analyses even the data that lacks a structure. The employment of multiple techniques enables us to have in depth knowledge about the industry and the further requirement of the industry.

The information that presents the in depth knowledge of the industry paving way for its improvement seeks the cloud infrastructure for storage purpose and any time access, from the management side to proceeds with measures of improving the production procedures. This causes the regular status of the industrial sections such as, shop floor, machine health, mishappenings and other activities leading to production cutting down or the normal activities to be updated over the internet to the cloud storage for anytime and anywhere access of the conditions prevailing in the industries. The information retrieved from the data procured are also stored into the cloud, for further reference in

ISSN: 2582-337X (online) 
Journal of Ubiquitous Computing and Communication Technologies (UCCT) (2019)

Vol.01/ No. 01

Pages: $13-22$

https://www.irojournals.com/jucct/

DOI: https://doi.org/10.36548/jucct.2019.1.002

the future to minimize the challenges in manufacturing, to a certain extent, the fig .4 gives the different stages of the big data analytics and the facilities of the cloud storage.

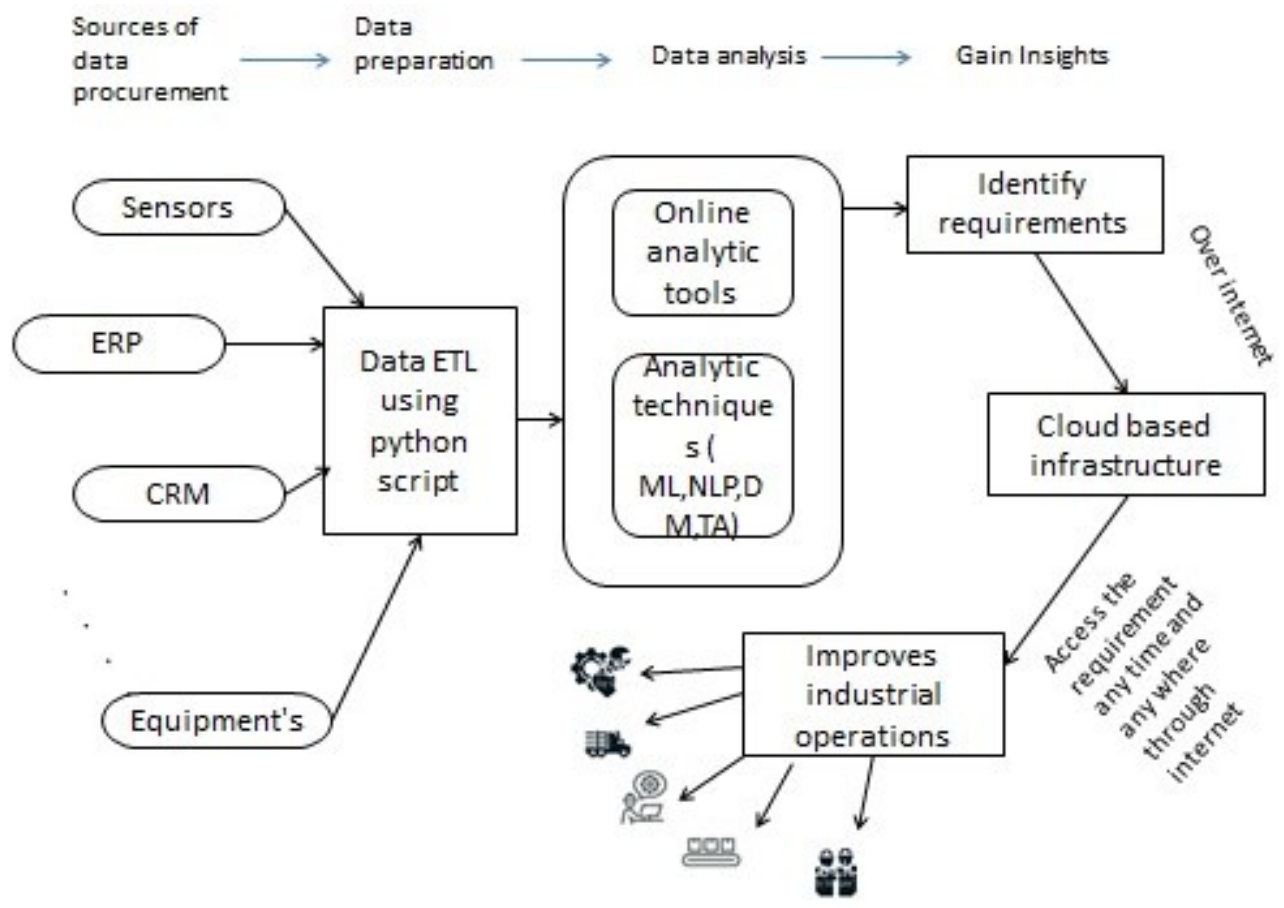

Fig. 4 Big Data Analytics in the Manufacturing Industry

\subsection{BENEFITS OF BIG DATA ANALYTICS IN THE INDUSTRIES}

The big data analytics in the process of the industrial development enables the industry to enjoy the certain benefits such as the minimizing the flaws in the process, the cost in production, inventory, management and the packaging. The big data ensures the enhancing of the efficiency in the work with improved forecasting enabling us to have actionable insights. Thus making the

- Business reputable and ever-relevant

ISSN: 2582-337X (online) 
Journal of Ubiquitous Computing and Communication Technologies (UCCT) (2019)

Vol.01/ No. 01

Pages: $13-22$

https://www.irojournals.com/jucct/

DOI: https://doi.org/10.36548/jucct.2019.1.002

- Reducing the production risk

- Reduced maintenance cost

- Enhanced supply chain visibility and productivity

- Reduced complexity and predictive knowledge

So the big data analytics enables to have insights that cause considerable development in the industry in various sections that are the manufacturing, logistics/supply chain, sales and marketing, research and development.

\section{RESULTS}

The application of the big data analytics that is intelligent applying the machine learning process, and the other techniques in the deriving the valuable information for the enormous data flow from the various section of the industry enables in meeting out the industrial requirement. Further causing an enhancement in the industrial operations. The prediction analysis provided by the machine learning process, would empower the big data analytics to be intelligent enough to perceive the future directions of the company stabilizing and consistent production and further reducing the cost of production and eluding the chances of production cutting down.

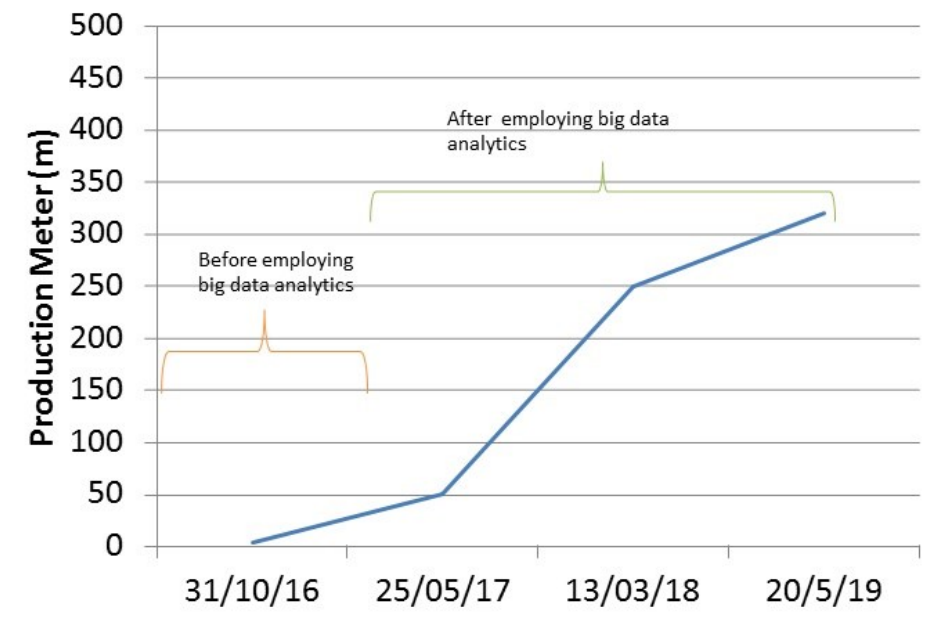

Fig.5 Production Report

ISSN: 2582-337X (online) 
Journal of Ubiquitous Computing and Communication Technologies (UCCT) (2019)

Vol.01/ No. 01

Pages: $13-22$

https://www.irojournals.com/jucct/

DOI: https://doi.org/10.36548/jucct.2019.1.002

The production report obtained before and after the application of the big data analytics is shown in the fig.5, the production report acquired from the production meter in the industry shows that the industry results with a considerable hike in the production after the application of the big data analytics, as the production cut downs and the chances of the production cut downs are eluded.

\section{CONCLUSION}

The paper proceeding with intelligent development of the big data analytics, of a manufacturing industry, procures data from various sources using the sensors, further prepares the data by cleaning applying the python scripts and proceeds with the analytics of the big data employing various intelligent techniques to visualize the in depth knowledge hidden inside the data, and enables us to decide with the further measures that are to be taken in enhancing the regular routines of the industry. The employment of the big data analytics in the industry enables to have risk free production, reducing the complexity and the maintenance cost and enhancing the visibility of the supply chain and the productivity. The business process involving the big data analytics become more relevant and renowned thus achieving an optimal throughput.

\section{References}

[1] Gandomi, Amir, and Murtaza Haider. "Beyond the hype: Big data concepts, methods, and analytics." International journal of information management 35, no. 2 (2015): 137-144. https://www.sciencedirect.com/science/article/pii/S0268401214001066

[2] Kambatla, Karthik, Giorgos Kollias, Vipin Kumar, and Ananth Grama. "Trends in big data analytics." Journal of Parallel and Distributed Computing 74, no. 7 (2014): 2561-2573.

[3] Hu, Han, Yonggang Wen, Tat-Seng Chua, and Xuelong Li. "Toward scalable systems for big data analytics: A technology tutorial." IEEE access 2 (2014): 652-687.

[4] Raghupathi, Wullianallur, and Viju Raghupathi. "Big data analytics in healthcare: promise and potential." Health information science and systems 2, no. 1 (2014): 3.

[5] Dai, Hong-Ning, Hao Wang, Guangquan Xu, Jiafu Wan, and Muhammad Imran. "Big data analytics for manufacturing internet of things: opportunities, challenges and enabling technologies." Enterprise Information Systems (2019): 1-25.

[6] Leenen, Louise, and Thomas Meyer. "Artificial Intelligence and Big Data Analytics in Support of Cyber Defense." In Developments in Information Security and Cybernetic Wars, pp. 42-63. IGI Global, 2019.

ISSN: 2582-337X (online)

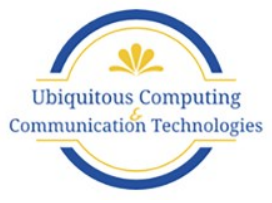


Journal of Ubiquitous Computing and Communication Technologies (UCCT) (2019)

Vol.01/ No. 01

Pages: $13-22$

https://www.irojournals.com/jucct/

DOI: https://doi.org/10.36548/jucct.2019.1.002

[7] Kibria, Mirza Golam, Kien Nguyen, Gabriel Porto Villardi, Ou Zhao, Kentaro Ishizu, and Fumihide Kojima. "Big data analytics, machine learning, and artificial intelligence in next-generation wireless networks." IEEE access 6 (2018): 32328-32338.

[8] Zhu, Li, Fei Richard Yu, Yige Wang, Bin Ning, and Tao Tang. "Big data analytics in intelligent transportation systems: A survey." IEEE Transactions on Intelligent Transportation Systems 20, no. 1 (2018): 383-398.

[9] De La Fuente, José, Margarita Villar, Agustin Estrada-Peña, and José A. Olivas. "High throughput discovery and characterization of tick and pathogen vaccine protective antigens using vaccinomics with intelligent Big Data analytic techniques." Expert review of vaccines 17, no. 7 (2018): 569-576.

[10] Chiang, Roger HL, Varun Grover, Ting-Peng Liang, and Dongsong Zhang. "Strategic value of big data and business analytics." (2018): 383-387.

[11] Wang, Lizhe, Yan Ma, Jining Yan, Victor Chang, and Albert Y. Zomaya. "pipsCloud: High performance cloud computing for remote sensing big data management and processing." Future Generation Computer Systems 78 (2018): 353-368.

[12] https://www.msrcosmos.com/blog/challenges-of-the-manufacturing-industry-big-data-analytics/

ISSN: 2582-337X (online) 